\title{
O uso de cores em cilindros contendo gás - Uma análise sobre a percepção visual sob diferentes iluminantes
}

\author{
Fabiana Rodrigues Leta \\ Márcia Pimenta Velloso \\ Andrea Rozendo M. dos Santos \\ UFF
}

\begin{abstract}
Resumo
Este artigo apresenta uma análise sobre a percepção visual humana das cores adotadas na indústria. Para tanto, foi desenvolvido um ambiente experimental no qual objetos, simulando cilindros contendo gases, com cores variadas foram submetidos a diferentes fontes de iluminação. Um grupo de observadores foi submetido ao experimento respondendo a um questionário. Os resultados deste experimento demonstram que a percepção de cores no ambiente industrial exerce influência direta na qualidade dos serviços e na segurança dos indivíduos que freqüentam tais instalações. A confusão observada na detecção das cores e associação das mesmas a características de periculosidade demonstra a necessidade de se analisar com cautela a adoção de determinadas cores na indústria. Os resultados mostram que a evolução das tecnologias de iluminação e de pigmentos deve ser acompanhada por normas e leis, especialmente em ambientes industriais envolvendo riscos.
\end{abstract}

Palavras-chave

Segurança industrial, iluminação, cor, fator de risco, ergonomia.

\section{Color use in gas cylinders - A visual perception analysis under different lighting}

\begin{abstract}
This article presents a methodology to study how the human being perceives and express the risk characteristic of gas cylinders colors in common conditions. This work deals with different color hues, submitted to different lighting. We present a discussion about risk factors involving changes of color perception depending on lighting source. It is based on empirical study of color perception in industrial environments. It influences the quality of the services and the employees' safety. We have as main goal start a discussion about the principal concepts involving color perception and lighting. The obtained results demonstrate the necessity of standardization concerning the color use, considering the appropriate lighting in industrial situations involving risks.
\end{abstract}

Key words

Industrial safety, color, lighting, risk factor, ergonomic. 


\section{INTRODUCC̄̃O}

Poder-se-ia supor que a industrialização automatizada simplificaria as tarefas visuais. Na verdade, tal feito não acontece. A vida moderna cada vez mais sobrecarrega os olhos, fazendo-os controladores constantes no discernimento de detalhes, no julgamento de diferenças e na leitura de telas de vídeo. Pelo sistema de visão humano passam oitenta por cento das informações concernentes ao mundo externo (GRIFFITH; LEONARD, 1997).

Sendo a cor o atributo mais evidente de um produto, a qualidade deste retrata-se inicialmente na fidelidade da cor. As tolerâncias admissíveis na diferença de cor obrigam a cuidados na formulação da cor, com implicações nos aspectos de reprodutibilidade, estabilidade e longo período de envelhecimento. E se a cor é componente do produto industrial, também é importante na organização do ambiente da produção industrial. A cor afeta a atividade humana, ao nível psicológico e fisiológico, com reflexos na atividade do córtex, do sistema nervoso reflexivo e atividade hormonal. A cor influencia o estado emocional, as impressões objetivas, subjetivas e o próprio estado de espírito. A cor afeta a percepção que se tem de volume, peso, temperatura, tempo, odores e ruídos (LETA et al., 2002).

\section{ERGONOMIA: SEGURANCQA E EFICIÊNCIA}

A ergonomia contribui para melhorar a eficiência, a confiabilidade e a qualidade das operações industriais. Isso pode ser feito basicamente por três vias: aperfeiçoamento do sistema homem-máquina, organização do trabalho e melhoria das condições de trabalho (LIDA, 1995).

A ergonomia tem sido a base para muitas readaptações nos últimos anos. Algumas pessoas podem ter a impressão de que os projetos de carros, mesas ou teclados de computador com design ergonômico são baseados em descobertas recentes para solução de problemas diários. Mas, muito do trabalho ergonômico envolvido nesses produtos consiste na utilização de medidas antropométricas que produtores desenvolveram. $\mathrm{O}$ aspecto mais importante da prática ergonômica é freqüentemente ignorado, este consiste em utilização eficiente e segura desses produtos. Uma das principais regras da ergonomia tem sido tirar proveito do estereótipo da população para determinar os locais e modos de operação de controles. Esse princípio também é aplicado no desenvolvimento de procedimentos de segurança de operação de todos os tipos de equipamentos (LIDA, 1995).

Uma segunda categoria de atuação da ergonomia está relacionada com os aspectos organizacionais do trabalho, procurando reduzir a fadiga e a monotonia, principalmente pela eliminação do trabalho altamente repetitivo, dos ritmos mecânicos impostos ao trabalhador e da falta de motivação provocada pela pouca participação do mesmo nas decisões sobre o seu próprio trabalho.

Em terceiro lugar, a melhoria das condições de trabalho é feita pela análise das condições

Por isso, a cor deve ser considerada, em termos ergonômicos e de segurança, no quadro da arquitetura e desenho de ambientes industriais. Além do nível de iluminação correto, a cor deve proporcionar um ambiente que reduza a fadiga prematura (nesse caso, o controle de contrastes de luminância e complementaridade de cores e a redução de pós-imagem são fundamentais), reduza o estresse, minimize erros e contribua para a orientação, equilíbrio e segurança. Cada caso deve ser objeto de estudo particular, levando-se em consideração as operações e equipamentos empregados, as características dos produtos, o tipo de iluminação e as dimensões da planta industrial (KWALLEK; LEWIS, 1990; SOARES, 1993). Seria vantajoso que apenas a cor fosse um sinal de que algum tipo de perigo está presente. Como, por exemplo, nos cilindros armazenadores de gases. Acredita-se que as cores mais utilizadas são sugeridas como as que são melhor associadas com o nível de risco de um perigo. É exatamente a existência ou não desta correlação que se procura investigar nesta pesquisa. físicas do trabalho, como temperatura, ruídos, vibrações, gases sobre uma tarefa que exige precisão pode ser muito fatigante. Por outro lado, focos de luz brilhantes colocados dentro do campo visual podem provocar ofuscamentos extremamente desconfortáveis (LIDA, 1995).

$\mathrm{O}$ aperfeiçoamento do sistema homem-máquina pode ocorrer tanto na fase de projeto de máquinas, equipamentos e postos de trabalho, como na introdução de modificações em sistemas já existentes, adaptando-os às capacidades e limitações humanas. Ou seja, em alguns casos, para se aumentar a segurança de utilização de um produto é necessário refazer seu projeto para que se eliminem os perigos. Em outros casos, materiais de proteção mantêm o usuário fora de contato com o perigo. Entretanto, quando nenhuma dessas alternativas é viável, avisos sobre os riscos são necessários (CHAPANIS, 1994). Como este aviso será apresentado é relevante para sua utilização eficiente. Ele deve estar localizado de forma que o usuário tenha acesso fácil, deve ser claro e entendido por todos os usuários em potencial, não tóxicos e iluminação. Por exemplo, uma iluminação deficiente 
importando seu nível de instrução, e, claro, deve chamar a atenção. Se um aviso dessa natureza não chamar a atenção, é equivalente a não existir aviso nenhum.

Um aspecto do processo de captação de atenção é a utilização de cores nos avisos. A ABNT especifica as cores que devem ser utilizadas para segurança (ABNT, 1995). As cores são utilizadas em várias circunstâncias em que a atenção é importante (HOFFMAN, 2001). Então, o modo como elas devem ser utilizadas em avisos de advertência é realmente fundamental.

\section{METODOLOGIA}

\section{Ambiente Experimental e Definição das Cores}

Um cilindro pode armazenar vários tipos de gases. Para auxiliar a identificação do conteúdo de cada um deles, a ABNT padronizou cores para os cilindros relacionando-as a cada tipo de gás. Como ponto de partida para a pesquisa em relação à percepção dessas cores nas indústrias, toma-se como base o catálogo utilizado pela empresa White Martins. Como a variedade de gases, não apenas industriais, mas medicinais, especiais e outros, é muito grande, foram selecionados inicialmente trinta deles, levando-se em consideração seu nível de periculosidade e suas cores correspondentes. Entretanto, o aspecto ligado às cores teve prioridade, pois estas, além de não serem facilmente reconhecíveis, são confundidas umas com as outras e mudam constantemente com pequenas alterações na iluminação, devido a todos os fatores destacados ao longo deste artigo.

Os gases escolhidos podem ser agrupados em três classes distintas: (a) os não-inflamáveis/tóxicos/corrosivos (como cloro e amônia);

(b) os inflamáveis/baixa toxicidade/não-corrosivos (como metano, hidrogênio e etileno);

(c) os não-inflamáveis/baixa toxicidade/não-corrosivos (como oxigênio, hélio, argônio e nitrogênio).

A lista destes gases e as respectivas cores de seus cilindros, segundo classificação do Sistema Munsell (JACKSON et al., 1994; ABNT, 1992), encontram-se nas Tabelas 1, 2 e 3. O Sistema Munsell é caracterizado por um espaço tridimensional constituído por cor, saturação e brilho (JACKSON et al., 1994; LOZANO, 1978).

\section{enfoque principal desta pesquisa foi a percepção de cor de cilindros de gases industriais.}

O grupo de cilindros de gases industriais foi escolhido por ter as cores muito bem caracterizadas, com poucos detalhes. Pode-se observar que os gases especiais e medicinais, na sua maioria, são representados por duas cores (uma referente ao corpo e outra referente à parte superior do cilindro). Além disso, o enfoque principal desta pesquisa foi a percepção de cor de cilindros de gases industriais.

É importante observar, através das fotos apresentadas na Figura 1, que o estado de conservação dos cilindros também afeta a percepção de suas cores, pois, muitas vezes, encontram-se arranhados, oxidados, amassados e/ou empoeirados.

Tabela 1: Gases industriais.

\begin{tabular}{|c|c|c|}
\hline GASES INDUSTRIAIS & COR & NOTAÇÃO MUNSELL \\
\hline Ar Comprimido & Azul claro & $10 \mathrm{~B} 5 / 10$ \\
\hline Argônio & Marrom & $5 Y R 2 / 4$ \\
\hline Dióxido de Carbono Sistema Incêndio & Vermelho & 5R $4 / 14$ \\
\hline Etil 5 & Violeta e Cinza & $5 P$ 7/6 e N7 \\
\hline Hélio & Alaranjado & $2,5 Y R 5 / 14$ \\
\hline Gases Refrigerantes & Branco & N9,5 \\
\hline Hidrogênio & Amarelo & $1,2 Y 7,5 / 14$ \\
\hline Metano ou GNV & Rosa seco & $2,5 Y R 8 / 4$ \\
\hline Mistura Conservante & Bege com detalhe marrom & 10YR $7 / 4$ e $5 Y R ~ 2 / 4$ \\
\hline Nitrogênio & Cinza & N7 \\
\hline Nitrogênio Sistema de Incêndio & Cinza e vermelho & N7 e $5 R$ 4/14 \\
\hline Oxigênio & Preto & N1 \\
\hline
\end{tabular}


Tabela 2: Gases especiais.

\begin{tabular}{|l|l|l|}
\hline \multicolumn{1}{|c|}{ GASES ESPECIAIS } & \multicolumn{1}{c|}{ COR } & \multicolumn{1}{|c|}{ NOTAÇÃO MUNSELL } \\
\hline Amônia & Turquesa claro e Bordô & 7,5BG 8/2 e 7,5R 3/8 \\
\hline Ar Sintético & Preto, Cinza e Bordô & N1 ; N7 e 7,5R3/8 \\
\hline Argônio & Marrom e Bordô & 5YR 2/4 e 7,5R 3/8 \\
\hline Nitrogênio & Cinza e Bordô & N7 e 7,5R 3/8 \\
\hline Etileno & Violeta e Bordô & 5 P 7/6 e 7,5R 3/8 \\
\hline Halocarbono & Branco e Bordô & N9,5 e 7,5R 3/8 \\
\hline Hélio & Alaranjado e Bordô & $2,5 Y R$ 5/14 e 7,5R 3/8 \\
\hline Hidrogênio & Amarelo e Bordô & $1,2 Y 7,5 / 14$ e 7,5R 3/8 \\
\hline Metano & Rosa seco e Bordô & $2,5 Y R$ 8/4 e 7,5R 3/8 \\
\hline Óxido Nitroso AA & Branco, Azulão e Bordô & N9,5 ; 5PB 2/6 e 7,5R 3/8 \\
\hline Oxigênio & Preto e Bordô & N1 e 7,5R 3/8 \\
\hline
\end{tabular}

Tabela 3: Gases Medicinais.

\begin{tabular}{|l|l|l|}
\hline \multicolumn{1}{|c|}{ GASES MEDICINAIS } & \multicolumn{1}{c|}{ COR } & \multicolumn{1}{c|}{ NOTAÇÃO MUNSELL } \\
\hline Ar Comprimido Medicinal & Cinza e Verde & N7 e 10GY \\
\hline Dióxido de Carbono USP & Cinza, Verde e Bordô & N7; 10GY e 7,5R 3/8 \\
\hline Mistura Carbogênica & Cinza, Verde e Bordô & N7 ; 10GY e 7,5R 3/8 \\
\hline Mistura Especial Medicinal & Bege, verde e Bordô & $10 Y R 7 / 4 ; 10 G Y$ e 7,5R 3/8 \\
\hline Mistura Odontare & Bege e Verde & $10 Y R$ 7/4 e 10GY \\
\hline Óxido Nitroso & Azulão & 5PB 2/6 \\
\hline Oxigênio & Verde & $10 G Y$ \\
\hline
\end{tabular}

Figura 1: Cilindros de gás em situação real de uso.

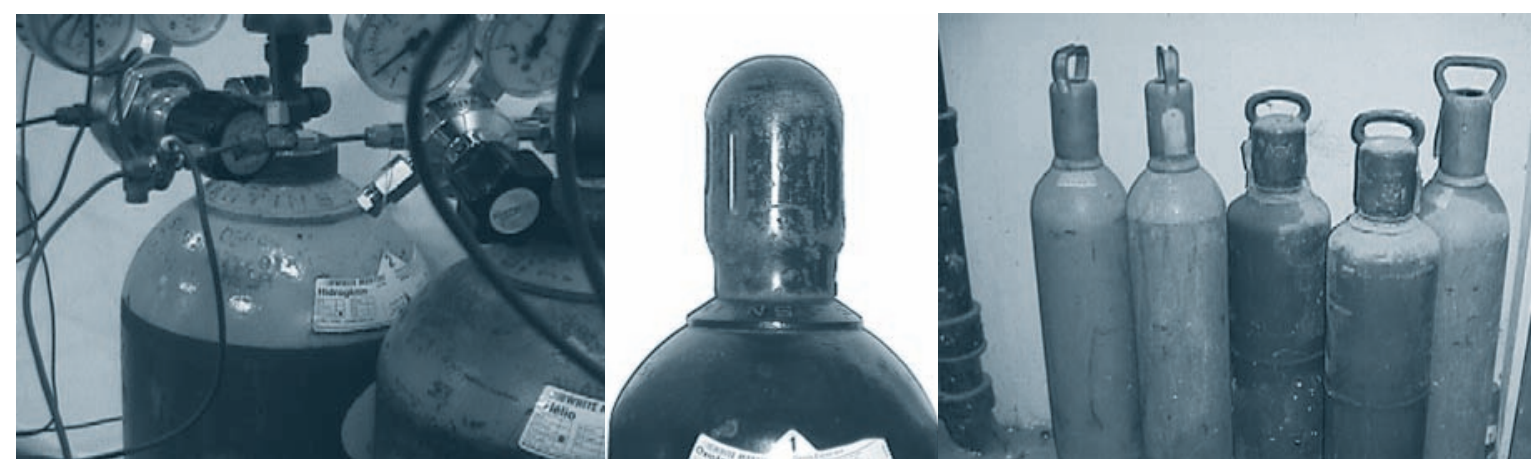


Tendo sido feita a escolha dos gases, foram confeccionados trinta cilindros em madeira de $10 \mathrm{~cm}$ de comprimento e 20 $\mathrm{mm}$ de diâmetro, pintados com as cores encontradas no painel da White Martins. Estes foram numerados para facilitar as respostas do questionário. Para possibilitar a troca de lugar entre os cilindros, inerente à pesquisa, construiu-se uma base com 60 furos (para encaixe dos cilindros) e esta foi colocada no chão do protótipo do ambiente industrial (a caixa). Este ambiente foi confeccionado de modo a permitir a troca de iluminantes durante o experimento (figura 2) (SANTOS, 2003). Esta troca é fundamental, tendo em vista que em ambientes industriais podem ocorrer múltiplas situações de iluminamento, o que leva a variadas percepções de cor de um mesmo objeto (LETA; VELLOSO, 2004; LETA et al., 2002).

Figura 2: Ambiente experimental.

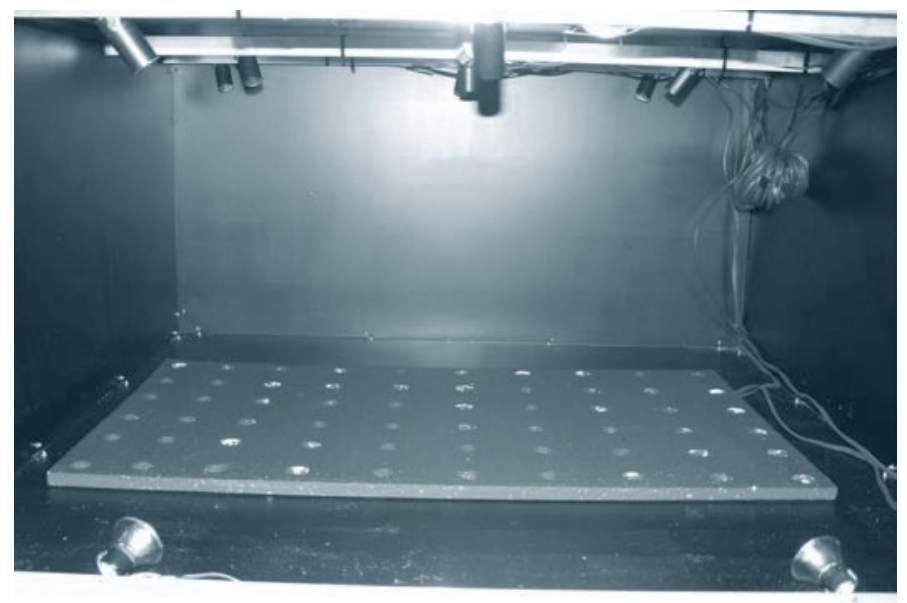

Figura 3: Painel da White Martins e simulações.

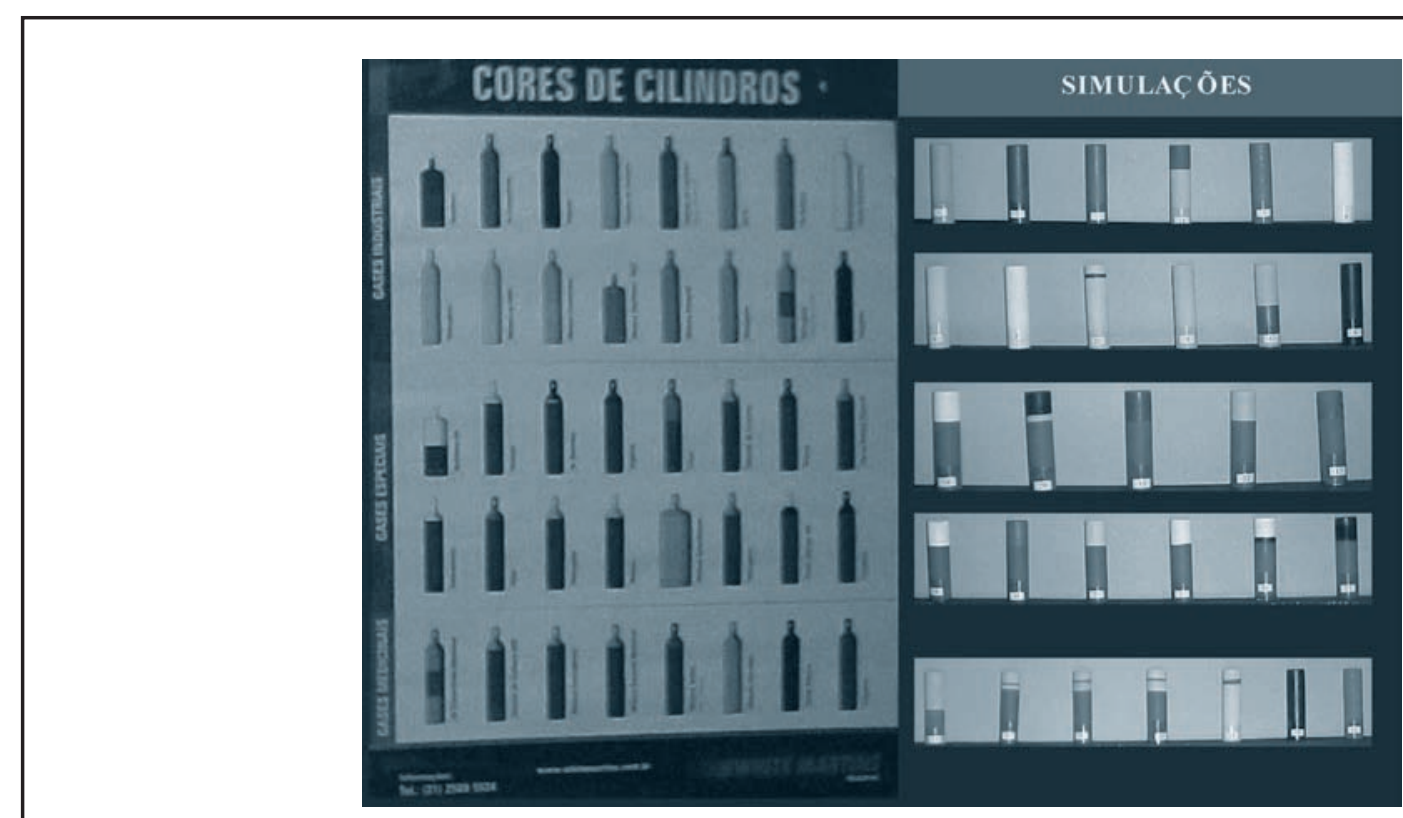


O painel da White Martins e os cilindros de madeira correspondentes podem ser observados na Figura 3.

\section{Testes presenciais}

Dos 30 cilindros de madeira confeccionados, 12 foram escolhidos para a realização dos testes, sendo todos eles correspondentes a gases industriais (SANTOS, 2003). O posicionamento aleatório dos 12 cilindros escolhidos é apresentado na Figura 4, e na Tabela 4 têm-se as características quanto a cor e tipo de gás.

Estes cilindros foram posicionados de acordo com a ordem de apresentação dos cilindros de gases industrias do painel apresentado na Figura 3. A numeração dos cilindros foi feita também de modo aleatório.

O teste, então, consistiu na apresentação destes cilindros, submetidos a três tipos de iluminação diferentes (VS - vapor de sódio, MVM - multivapor metálico e I - incandescentes halógenas), conforme pode ser observado nas Figuras 5 a 7 .

Os grupos observavam o esquema montado e respondiam ao questionário. $\mathrm{O}$ objetivo das perguntas formuladas era o de avaliar as associações que os diferentes observadores fazem das cores em relação às questões de segurança, e ainda observar o quanto suas percepções se alteram quando

Figura 4: Posições dos cilindros.

\begin{tabular}{|l|l|l|l|l|l|l|}
\hline 1 & & 2 & & 3 & & 14 \\
\hline & 5 & & 4 & & 6 & \\
\hline 7 & & 25 & & 8 & & 12 \\
\hline & & & 9 & & & \\
\hline
\end{tabular}

Figura 5: Lâmpada de vapor de sódio acesa.

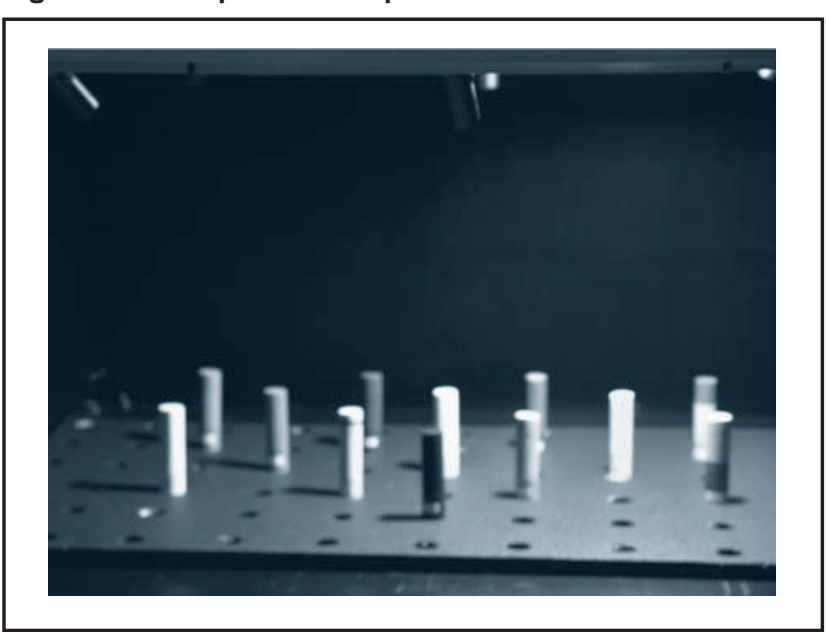

Figura 6: Lâmpada de multivapor metálico acesa.

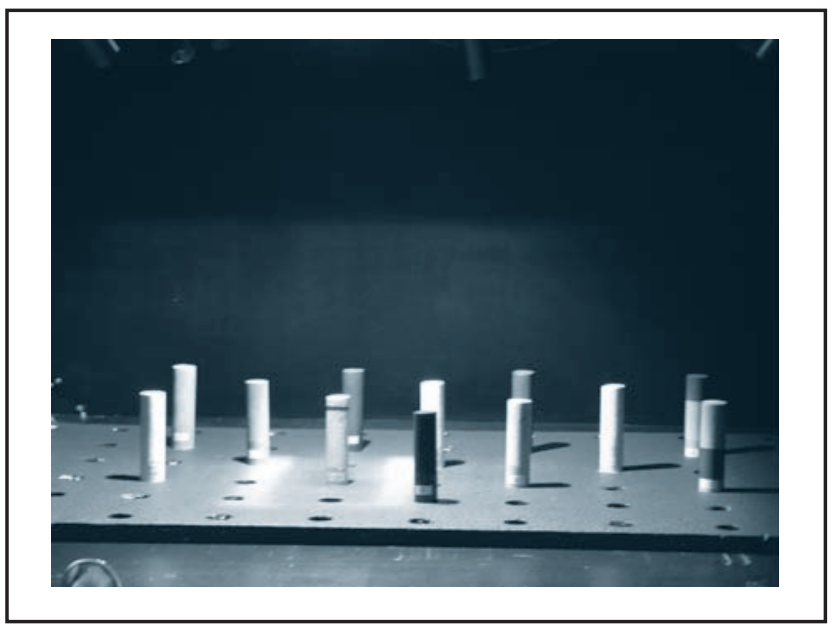

Tabela 4: Cilindros escolhidos para os testes presenciais.

\begin{tabular}{|c|c|c|c|}
\hline NÚMERO & COR & NOTAÇÃO MUNSELL & GÁs \\
\hline 1 & Azul claro & $10 B 5 / 10$ & Ar comprimido \\
\hline 2 & Marrom & $5 Y R 2 / 4$ & Argônio \\
\hline 3 & Vermelho & $5 R 4 / 14$ & Dióxido de carbono para sistema de incêndio \\
\hline 14 & Violeta e cinza & $5 P 7 / 6$ e N7 & Etil 5 \\
\hline 5 & Alaranjado & $2,5 Y R 5 / 14$ & Hélio \\
\hline 4 & Branco & N9,5 & Gases Refrigerantes \\
\hline 6 & Amarelo & $1,2 Y 7,5 / 14$ & Hidrogênio \\
\hline 7 & Rosa seco & $2,5 Y R$ 8/14 & Metano ou GNV \\
\hline 25 & Bege & - & Mistura Conservante \\
\hline 8 & Cinza & N7 & Nitrogênio \\
\hline 12 & Cinza e vermelho & N7 e $5 R$ $4 / 14$ & Nitrogênio para sistema de incêndio \\
\hline 9 & Preto & N1 & Oxigênio \\
\hline
\end{tabular}


Figura 7: Lâmpadas incandescentes halógenas acesas.

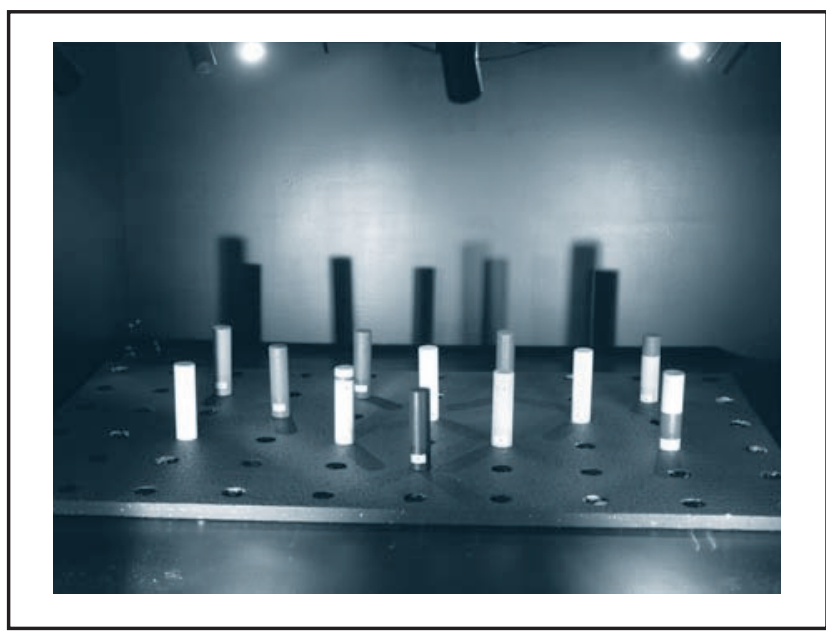

os objetos são iluminados com fontes de naturezas variadas. Nem todas as respostas do questionário foram utilizadas, pois algumas não estavam no foco desta pesquisa, tendo sido incluídas apenas para análise de trabalhos futuros.

Os grupos respondentes incluíam indivíduos com pouco ou até mesmo nenhum conhecimento de química e, conseqüentemente, das características dos gases, e também indivíduos com forte conhecimento na área. Foram testados
Figura 8: Grupos em teste.

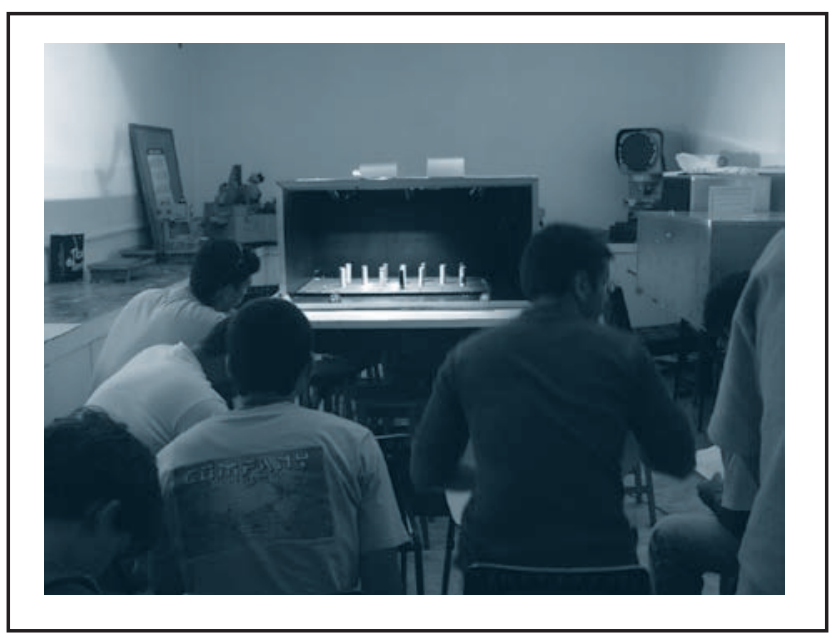

estudantes do curso de graduação e pós-graduação de engenharia, professores de diversas áreas, engenheiros elétricos, arquitetos e empregados da manutenção e da limpeza da universidade. A faixa etária variou de 18 a 63 anos, sendo assim possível futura avaliação das respostas de indivíduos considerando diferentes fases de maturidade da lente do olho. Assim, o nível de escolaridade ficou entre 1ำ grau incompleto a doutorado completo.

Tabela 5: Número de indivíduos respondentes por iluminante.

\begin{tabular}{|l|c|c|c|}
\hline & INGANDESCENTE & MULTIVAPOR & VAPOR DE SÓDIO \\
\hline Total de respondentes & 113 & 120 & 128 \\
\hline
\end{tabular}

Figura 9: Resultados gerais em relação à pergunta: Qual o cilindro que contém a substância mais perigosa para os três iluminantes?

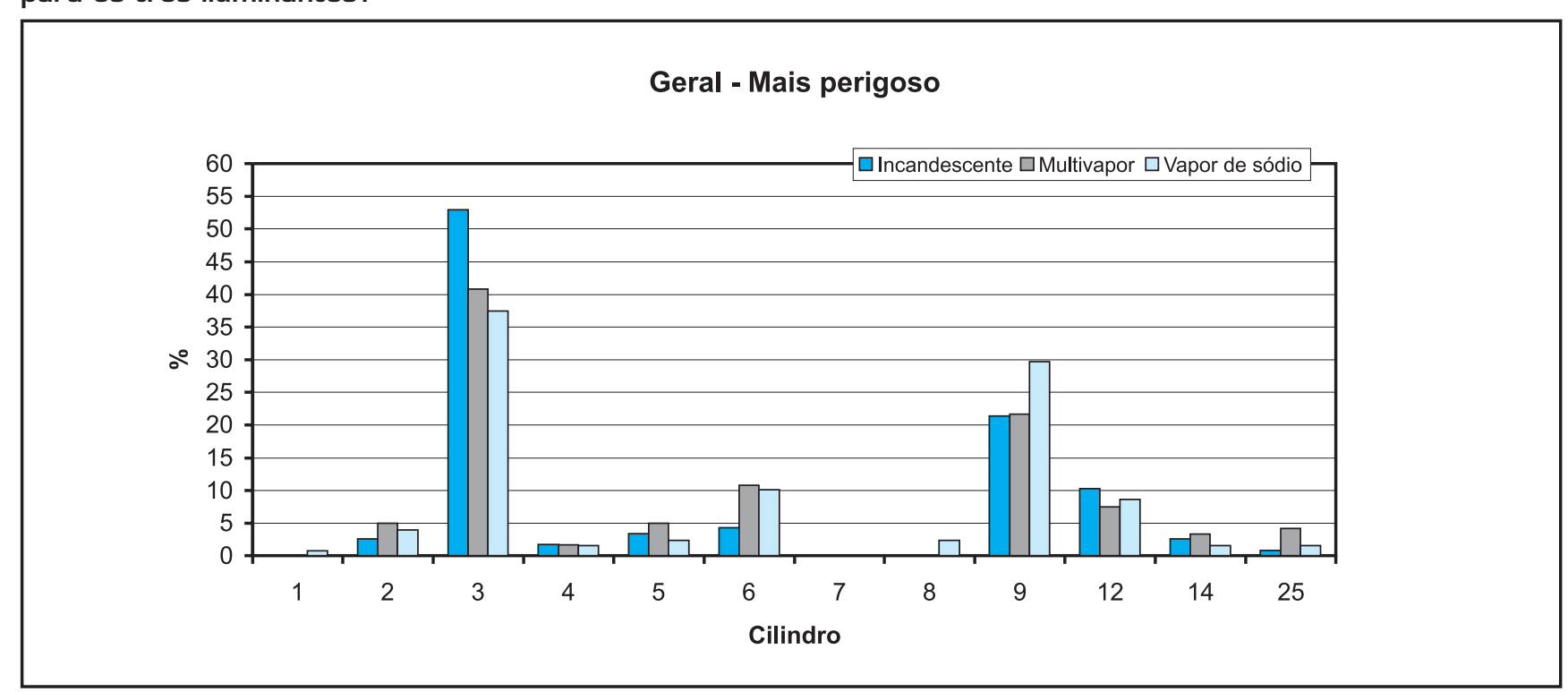


Na tabela seguinte apresenta-se o número de pessoas que respondeu ao questionário para cada tipo de iluminante. As comparações foram feitas considerando o grupo como um todo e não foi considerada uma comparação indivíduo a indivíduo.

\section{RESULTADOS}

No gráfico apresentado na Figura 9, temos os resultados da pergunta referente à cor que melhor seria associada ao perigo, sob a iluminação dos três tipos de lâmpadas.

O cilindro 3 (vermelho) aparece, não com a mesma proporção, mas de forma contundente para os três iluminantes como tendo a cor que identificaria a substância mais perigosa ao homem. Na terceira posição, apesar dos valores estarem em torno de $10 \%$, podemos sentir uma diferença na percepção para a lâmpada incandescente diferente da percepção das lâmpadas de vapor de sódio e multivapor metálico. Interessante notar que o cilindro 7 (rosa seco) não obteve qualquer indício de periculosidade e o cilindro 1 (azul claro) só obteve resposta menor que 5\% para a lâmpada MVM, estando zerado para os outros dois iluminantes.

$\mathrm{Na}$ Figura 10 temos os resultados obtidos referentes à pergunta sobre qual o cilindro que deve conter o gás menos perigoso.

O cilindro 4 aparece claramente como sendo aquele onde os entrevistados colocariam a substância menos perigosa ao homem, para os três iluminantes. Já para a segunda posição as dúvidas entre as cores e os iluminantes aparecem, havendo inclusive uma inversão entre a lâmpada incandescente e as outras duas. Interessante notar que o cilindro 7, que não obteve qualquer indício de periculosidade, aparece como sendo a terceira opção para dois iluminantes: vapor de sódio e multivapor metálico. Chamam atenção a percepção ocorri-

Tabela 6: Respostas mais significativas para a pergunta: Qual o cilindro que contém a substância mais perigosa?

\begin{tabular}{|l|c|c|c|}
\hline & INGANDESCENTE (I) & MULTIVAPOR METÁLICO (MVM) & VAPOR DE SÓDIO (VS) \\
\hline cilindro 3 & $>50 \%$ & $40 \%$ & $>35 \%$ \\
\hline cilindro 9 & $>20 \%$ & $>20 \%$ & $30 \%$ \\
\hline cilindro 6 & $<10 \%$ & $10 \%$ & $10 \%$ \\
\hline cilindro 12 & $10 \%$ & $<10 \%$ & $<10 \%$ \\
\hline
\end{tabular}

Figura 10: Resultados gerais em relação à pergunta: Qual o cilindro que contém a substância menos perigosa para os três iluminantes?

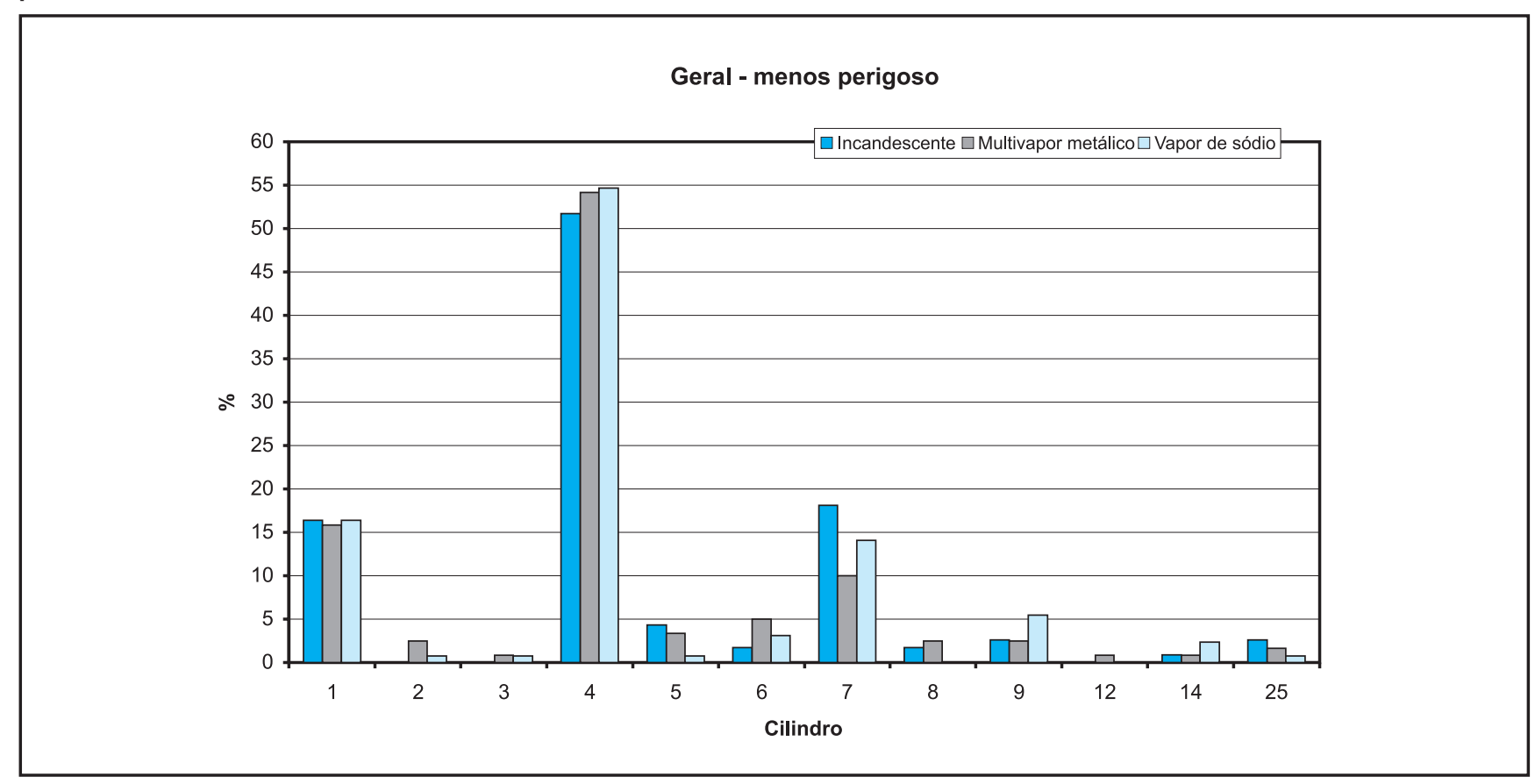


da para os cilindros 1 e 7 sob iluminação MVM para o mais perigoso e o menos perigoso. Analisando o gráfico da figura 9 seria esperado que o cilindro 1 fosse considerado menos perigoso do que o cilindro 7, para o mesmo iluminante.

Na Figura 11 temos o gráfico correspondente à pergunta sobre qual cilindro chama mais a atenção.

Quanto ao item atenção, o mesmo varia entre o três iluminantes e a resposta não coincide com o cilindro caracterizado como o mais perigoso, com exceção do cilindro 3 iluminado pela lâmpada incandescente.
Na Figura 12 apresentam-se os resultados relacionados à pergunta sobre qual cilindro seria retirado primeiro em uma situação de emergência.

Em situações de retirada em caso de emergência, o cilindro 3 seria o escolhido se sob iluminação incandescente ou MVM, mas se a iluminação fosse VS, apesar dos valores serem muito próximos, haveria uma preferência na retirada do cilindro 9 em relação ao cilindro 3 .

Pode-se observar que a seqüência de retirada dos cilindros seria diferente para cada iluminante.

Tabela 7: Respostas mais significativas para a pergunta: Qual cilindro contém a substância menos perigosa?

\begin{tabular}{|l|c|c|c|}
\hline & INGANDESGENTE (I) & MULTIVAPOR METÁLICO (MVM) & VAPOR DE SóDIO (VS) \\
\hline cilindro 4 & $>50 \%$ & $>50 \%$ & $>50 \%$ \\
\hline cilindro 1 & $15 \%$ & $15 \%$ & $15 \%$ \\
\hline cilindro 7 & $>15 \%$ & $10 \%$ & $>10 \%$ \\
\hline
\end{tabular}

Figura 11: Resultados gerais em relação à pergunta: Qual o cilindro que chama mais a atenção para os diferentes iluminantes?

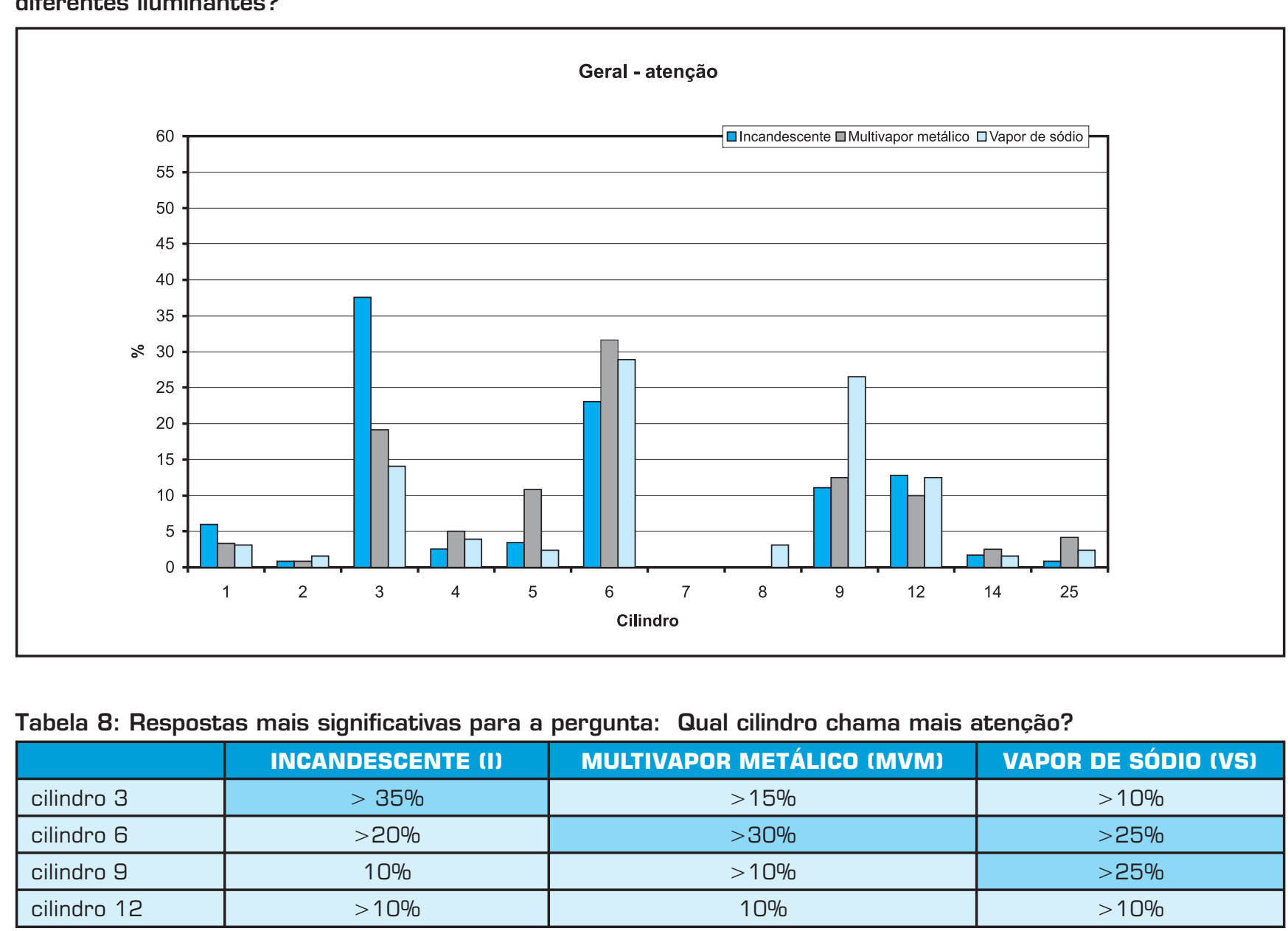


- Para a lâmpada incandescente: $3-9-12$

- Para a lâmpada MVM: $3-6-9$

- Para a lâmpada VS : $9-3-6$

Neste caso, a relação com a periculosidade mantém-se para as lâmpadas incandescente e MVM, diferindo na de VS, sendo que para a lâmpada incandescente fica mantida também a relação com o chamar atenção.

Na Figura 13 observam-se os resultados relacionados à pergunta sobre qual cilindro não seria retirado, por não ser considerado perigoso em uma situação de emergência.

No caso da não retirada em caso de emergência, o cilindro 4 seria o escolhido se sob iluminação incandescente ou MVM, mas se a iluminação fosse VS, apesar dos valores serem muito próximos, haveria uma preferência na retirada do cilindro 9 em relação ao cilindro 3 .

Pode-se observar que a seqüência de retirada dos cilindros seria diferente para cada iluminante.
- Para a lâmpada incandescente: $4-1-3$

- Para a lâmpada MVM: 4-1-9

- Para a lâmpada VS : $9-3-1$

Neste caso, a relação com a falta de periculosidade mantém-se para as lâmpadas incandescente e MVM.

Mas um fato relevante a ser observado na seqüência de retirada no que tange à periculosidade ou à ausência dela é que para a lâmpada incandescente o primeiro cilindro a ser retirado é o terceiro a ser deixado. Já para a MVM o terceiro cilindro a ser retirado ou a ser deixado é o mesmo. No caso da VS a situação é mais grave, já que os dois primeiros a serem retirados são também os dois primeiros a serem deixados.

$\mathrm{Na}$ Tabela 11 tem-se a consolidação dos dados apresentados nos gráficos e tabelas anteriores. Percebe-se que para as perguntas relativas a qual o cilindro que desperta mais atenção, qual o que se tira e qual o que não se tira em caso de

Figura 12: Resultados gerais em relação à pergunta: qual o cilindro que em uma situação de emergência deve ser removido primeiro, para os diferentes iluminantes.

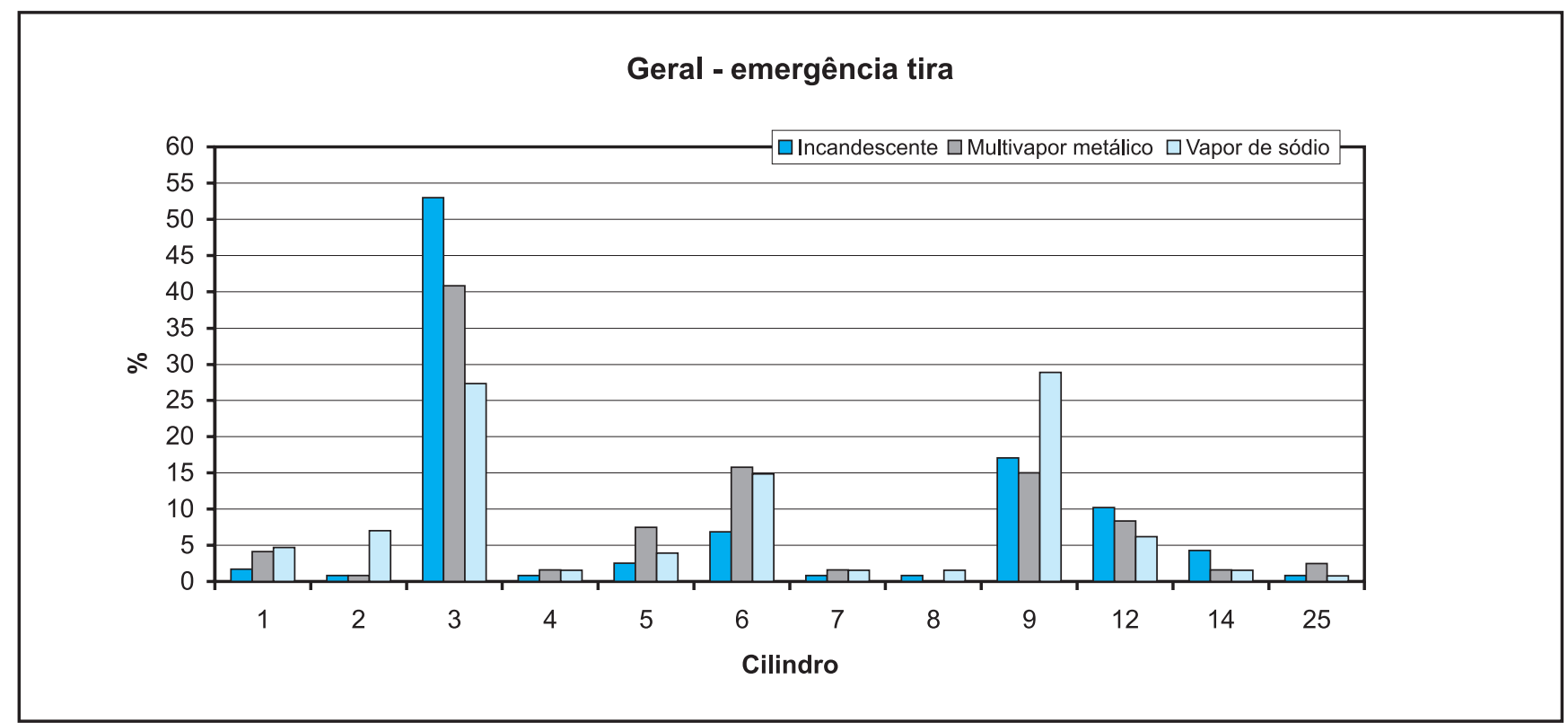

Tabela 9: Respostas mais significativas para a pergunta: Qual o cilindro que em caso de emergência seria o primeiro a ser retirado?

\begin{tabular}{|l|c|c|c|}
\hline & INGANDESGENTE (I) & MULTIVAPOR METÁLICO (MVM) & VAPOR DE SÓDIO (VS) \\
\hline cilindro 3 & $>50 \%$ & $40 \%$ & $>25 \%$ \\
\hline cilindro 6 & $>5 \%$ & $15 \%$ & $15 \%$ \\
\hline cilindro 9 & $>15 \%$ & $15 \%$ & $>25 \%$ \\
\hline cilindro 12 & $10 \%$ & $>5 \%$ & $5 \%$ \\
\hline
\end{tabular}


emergência, a iluminação influencia fortemente na escolha dos respondentes, especialmente a VS.

Para avaliar os riscos decorrentes de uma percepção diferenciada quanto a gases perigosos quando submetidos a diferentes fontes de iluminação, apresenta-se o grupo de periculosidade a que estes gases pertencem. Em destaque estão os cilindros com citações relevantes ao trabalho, em fundo claro encontram-se os cilindros que foram pouco citados.

Os grupos referem-se ao grau de periculosidade dos gases. O grupo 1 é caracterizado por ser não-inflamável, não-corrosivo e de baixa toxidez. O grupo 2 tem como característica ser inflamável, não corrosivo e de baixa toxidez.

É importante destacar as características de alguns gases citados:

Figura 13: Resultados gerais em relação à pergunta: Qual o cilindro que em uma situação de emergência não seria removido, para os diferentes iluminantes?

\section{Geral - emergência não tira}

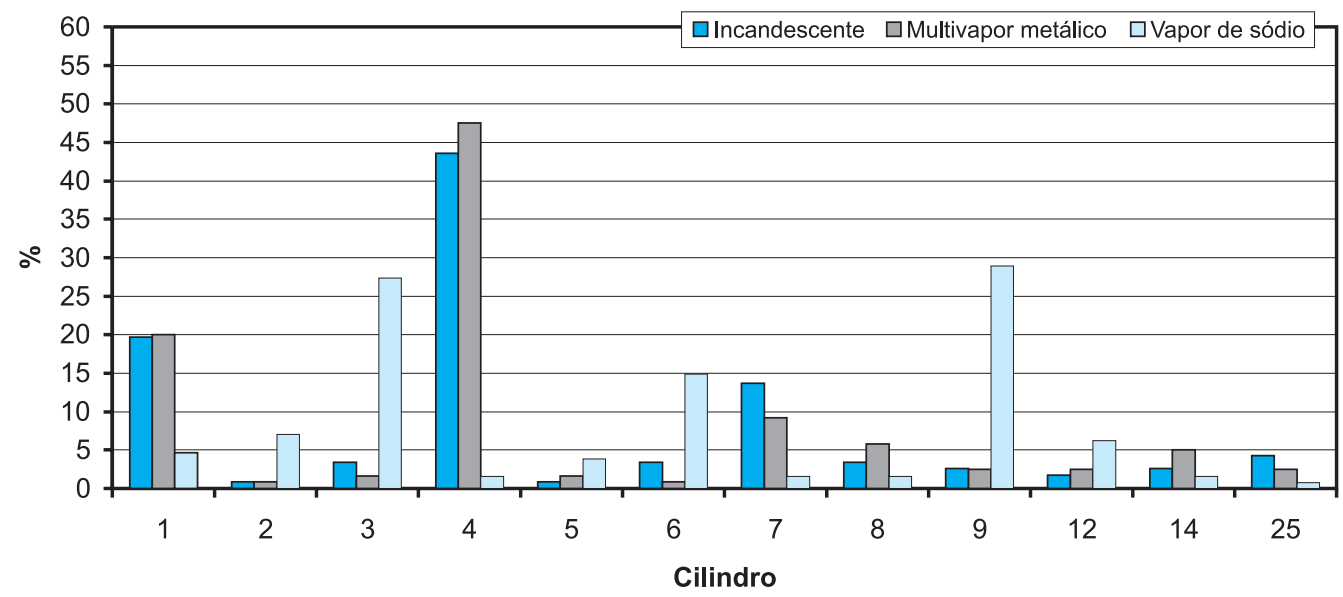

Tabela 10: Qual o cilindro que em caso de emergência não seria retirado?

\begin{tabular}{|l|c|c|c|}
\hline & INGANDESCENTE (I) & MULTIVAPOR METÁLICO (MVM) & VAPOR DE SÓDIO (VS) \\
\hline cilindro 1 & $20 \%$ & $20 \%$ & $<5 \%$ \\
\hline cilindro 3 & $<5 \%$ & $>5 \%$ & $>25 \%$ \\
\hline cilindro 4 & $>40 \%$ & $>45 \%$ & $<5 \%$ \\
\hline cilindro 9 & $>5 \%$ & $>5 \%$ & $>25 \%$ \\
\hline
\end{tabular}

Tabela 11: Consolidação dos dados.

\begin{tabular}{|l|c|c|c|}
\hline & INGANDESCENTE (I) & MULTIVAPOR METÁLICO (MVM) & VAPOR DE SÓDIO (VS) \\
\hline mais perigoso & 3 & 3 & 3 \\
\hline menos perigoso & 4 & 4 & 4 \\
\hline mais atenção & 3 & 6 & 6 \\
\hline emergência tira & 3 & 3 & 9 \\
\hline emergência não tira & 4 & 4 & 9 \\
\hline
\end{tabular}


1. Oxigênio (cilindro 9) - é não-inflamável, não-combustível, porém aumenta o fogo, aumentando as proporções de um incêndio. Em contato com óleo, graxa, estopa, madeira e outros materiais combustíveis e inflamáveis pode produzir chamas. Em contato com a pele e os olhos pode causar queimaduras.

algumas situações a cor é o principal indicador do grau de periculosidade de um equipamento, de uma tubulação ou de um cilindro de armazenamento de gás.

Apesar das brigadas de incêndio e do treinamento inicial do corpo técnico, nem sempre as pessoas encarregadas de liderarem uma evacuação estão no local ou mesmo em condições de atuar. Nestes casos não se pode depender apenas da informação técnica, advinda do treinamento e dos brigadistas. Ou seja, torna-se fundamental a percepção humana espontânea.

Os resultados, obtidos nesta pesquisa, demonstraram que em caso de acidente, quando a percepção de informação é fundamental

2. Acetileno (cilindro 3) - é inflamável e explosivo sobre alta pressão e temperatura. É também anestésico.

3. Hidrogênio (cilindro 6) - é inflamável e a rápida liberação do gás pode causar elevação de temperatura e conseqüente combustão. É não tóxico, mas pode atuar como asfixiante por deslocamento de ar ambiente.

\section{CONCLUSÕES}

Para aumentar a segurança de um produto, em ambientes industriais é comum o uso de cor como forma de diferenciação, além do texto de alerta. A forma de apresentação destes avisos é relevante para a transmissão da mensagem. $\mathrm{O}$ aviso deve ser claro e entendido por todos os usuários em potencial, não importando seu nível de instrução, e claro, deve chamar atenção. Se um aviso dessa natureza não chamar a atenção, é equivalente a não existir aviso nenhum. Em para minimizar os efeitos do próprio acidente, a confusão observada, na detecção das cores e associação das mesmas às características de periculosidade, demonstra a necessidade de se analisar com cautela a adoção de determinados iluminantes e determinadas cores na indústria.

$\mathrm{O}$ enfoque deste trabalho foi realizar um diagnóstico da percepção visual de cilindros de gases industriais sob diferentes iluminantes. Cabe observar que as Normas Técnicas Brasileiras estabelecem as cores dos cilindros e não os iluminantes a serem usados (SANTOS et al., 2005). Assim, há uma dissociação entre cor e iluminante que leva a diferentes percepções. Estas orientações não cumprem, portanto, com o objetivo de caracterizar a ausência ou não de perigo.

Apesar dos resultados indicarem as cores mais adequadas para cada situação de risco, sugere-se em trabalhos futuros uma profunda reflexão sobre as normas brasileiras atualmente adotadas e seus impactos na segurança industrial.

Tabela 12: Cilindros citados com freqüência relevante (em destaque) e demais cilindros.

\begin{tabular}{|c|l|l|c|}
\hline CILINDRO & \multicolumn{1}{|c|}{ GÁS } & PERICULOSIDADE \\
\hline 1 & Azul claro & Ar comprimido & Grupo 1 \\
\hline 3 & Vermelho & Dióxido de carbono para sistema de incêndio & Grupo 1 \\
\hline 4 & Branco & Gases Refrigerantes & Grupo 1 \\
\hline 6 & Amarelo & Hidrogênio & Grupo 2 \\
\hline 7 & Rosa seco & Metano ou GNV & Grupo 2 \\
\hline 9 & Preto & Oxigênio & Grupo 1 \\
\hline 12 & Cinza e vermelho & Nitrogênio para sistema de incêndio & Grupo 1 \\
\hline 2 & Marrom & Argônio & Grupo 1 \\
\hline 14 & Violeta e cinza & Etil 5 & Grupo 2 \\
\hline 5 & Alaranjado & Hélio & Grupo 1 \\
\hline 25 & Bege & Mistura Conservante & Grupo 1 \\
\hline 8 & Cinza & Nitrogênio & Grupo 1 \\
\hline
\end{tabular}




\section{Artigo recebido em 25/03/2004 Aprovado para publicação em 24/11/2005}

\section{- Referências Bibliográficas}

ASSOCIAÇÃO BRASILEIRA DE NORMAS TÉCNICAS. NBR 12694: Especificação de cores de acordo com o sistema de notação Munsell, ABNT, 1992.

ASSOCIAÇ̃̃O BRASILEIRA DE NORMAS TÉCNICAS. NBR 7195: Cores para segurança, ABNT, 1995

CHAPANIS, A. Hazards associated with three signal words and four colours on warning signs. Ergonomics, v. 37.2, p. 265-275, 1994

GRIFFITH, L. J.; LEONARD, S. D. Association of colors with warning signal words. International Journal of Industrial Ergonomics. Elsevier, v. 20, p. 317-325, 1997.
HOFFMAN, D. Inteligência visual: Como criamos o que vemos. Rio de Janeiro: Campus, 2001.

JACKSON, R.; MACDONALD, L.; FREEMAN, K. Computer Generated Color - A practical guide to presentation and display. Reino Unido, John Wiley \& Sons, 1994.

KWALLEK, N.; LEWIS, C. M. Effects of environmental colour on males and females: A red or white or green office. Applied Ergonomics, v. 21.4, p. 275 -278, 1990

LEONARD, S.D. Does color of warnings affect risk perception? International Journal of Industrial Ergonomics. Elsevier, v. 23, p. 499-504, 1997.
LETA, F.; ARAÚJO, R. M.; VELLOSO, M. P. Qualitative measurement of colour based on human perception. CGIV: The First European Conference on Colour in Graphics, Image and Vision, 2002.

LETA, F. R.; VELLOSO, M. M. P. Medida Qualitativa de Cor e de Iluminantes Baseada na Percepção Humana. Revista Produto \& Produção, a publicar, 2004.

LIDA, Itiro. Ergonomia: Projeto e produção. 3. ed. São Paulo: Editora Edgard Blücher, 1995.

LOZANO, R. D. El color y su medición. Argentina: Editorial Américalee.1978.
SANTOS, A. R. M. dos. Percepção de Cores em Ambientes Industriais. Dissertação de Mestrado, Programa de Pós-Graduação em Engenharia Mecânica, Universidade Federal Fluminense, 2003.

SANTOS, A. R. M. dos; LETA, F. R.; VELLO SO, M. V. Fatores de risco industrial causados por diferentes percepções de cores devido à diferença de iluminantes. Revista Produção On Line, v. 5, n. 1, mar. 2005.

SOARES, O. D. D. A Gestão da cor pelo homo color. Portugal: Editora CETO 1993.

\section{- Agradecimentos}

À FAPERJ (Projeto Temático Metrologia baseada em Visão Computacional) pelo apoio financeiro. Aos engenheiros Públio Lima de Mello e Salomão Miguel Jabbour pelas trocas de idéias no âmbito de normas técnicas. Ao técnico do Laboratório de Metrologia Dimensional e Computacional Alain Jannuzzi, pelo apoio no projeto do protótipo experimental.

\section{- Sobre os autores}

\section{Fabiana Rodrigues Leta, DSc}

Programa de Pós-Graduação em Engenharia Mecânica - UFF

End.: R. Passo da Pátria, 156, Niterói - RJ

Tel: (21) 2629-5460, Fax: (21) 2629-5394

E-mail: fabiana@ic.uff.br

\section{Márcia Pimenta Velloso, DSc}

Programa de Pós-Graduação em Engenharia Civil - UFF

End.: R. Passo da Pátria, 156, Niterói - RJ

Tel: (21) 2629-5575

E-mail: marcia@pimentavelloso.org

\section{Andrea Rozendo M. dos Santos, MSc}

Programa de Pós-Graduação em Engenharia Mecânica - UFF

End.: R. Passo da Pátria, 156, Niterói - RJ

Obs.: As fotos apresentadas neste artigo podem ser vistas em cores no endereço: http://www.lmdc.uff.br/equipe/fabianaleta 